\title{
An incidental detection of aortic aneurysm on Tc-99m VIA63 renal scintigraphy
}

Murat Sadic, Koray Demirel, Gökhan Koca, Hasan Ikbal Atilgan, Meliha Korkmaz

Ministry of Health Ankara Training and Research Hospital, Department of Nuclear Medicine, Ankara, Turkey

[Received 17 III 2013; Accepted 10 VI 2013]

\section{Abstract}

A 71-year-old man with newly diagnosed hypertension was referred for Technetium-99m mercaptoacetyltriglycine (Tc-99m MAG3) renal scintigraphy to evaluate the recent onset of impairment in renal functions. Dynamic imaging revealed activity flow which was suspicious for aortic aneurysm (AA) with a concurrent decrease in left renal blood flow. CT angiography of the thoracoabdominal aorta confirmed that this area corresponded to $A A$. The purpose of this report was to present the first case of incidental detection of AA on Tc-99m MAG3 scintigraphy and highlight the importance of correlative imaging for the diagnosis of abnormal radioactivity accumulation in the region of vascular structures.

KEY words: aortic aneurysm, Tc-99m MAG3, renal scintigraphy, CT angiography

Nuclear Med Rev 2013; 16, 2: 97-99

\section{Figure 1}

Tc-99m MAG3 renal scintigraphic images. Camera parameters: posterior position, $15 \%$ window centered at $140 \mathrm{keV}$ using $64 \times 64$ matrix. Acquisition was started with bolus injection of $185 \mathrm{MBq}(5 \mathrm{mCi})$ Tc-99m MAG3 and dynamic imaging was performed at 2 seconds/frame for 16 frames and then 2 minutes/frame for 19 frames. Dynamic vascular phase imaging of renal flow scintigraphy with Tc-99m MAG3 demonstrated abnormal radiotracer accumulation that was suspicious for abdominal AA and decreased

Correspondence to: Murat Sadic

Department of Nuclear Medicine

Ministry of Health, Ankara Training and Research Hospital, Ulucanlar Street,

06340 Ankara, Turkey

Tel.: +903125953608

Fax: +90 3125953856

E-mail:mdmuratsadic@gmail.com left renal blood flow (A, B, black arrows). The entire 40-minute dynamic posterior imaging demonstrated diminished extraction and excretion functions in the left kidney $(\mathbf{B})$. According to these images, CT angiography was performed to confirm the suspected AA and to delineate the relationship of the aneurysm to the renal arteries.

Abdominal aortic aneurysm, defined as a permanent dilatation of the abdominal aorta to a size $50 \%$ greater than the normal segment, is thought to be a degenerative change of alteration in elastin and collagen and enzymatic degradation in the aortic wall $[1,2]$. Increased age, smoking, male sex and family history are the major risk factors for developing AA [3, 4]. Duplex Ultrasonography is the most common modality to detect AA and CT angiography is the first choice of imaging studies to define the diameter of the aorta and suspected renal artery involvement in a patient with AA [4]. The scintigraphic first pass (blood flow) or blood pool studies may show unusual abdominal or thoracic features suggestive of aneurysm as an incidental finding [5-9].

\section{Figure 2}

CT angiography examination of thoracoabdominal aorta A. Three dimensional reconstruction image demonstrating fusiform aneurysmatic dilatation beginning from the ascending aorta extending to the iliac bifurcation, including the abdominal aorta; B. Sagittal view of AA; C. narrowed left renal artery (white arrow); D. Normal right renal artery (white arrow).

\section{Figure 3}

Corresponding contrast-enhanced computed tomography (CT) examination of the thoracoabdomen demonstrating a $69 \times 64 \mathrm{~mm}$ measured aortic aneurysm (A, upper arrowheads) with kyphoscoliosis, normal pelvicalyceal system and asymmetry in renal size with a smaller left kidney (A, left arrow) and normal right kidney (A, right arrow). CT transaxial scans at the renal level showed a large abdominal $A A$ with a lumen of $48 \times 35 \mathrm{~mm}$ with a mural thrombus (B, C, arrowheads).

Detecting aortic aneurysm with Tc-99m MAG3 renal scintigraphy is not at all common and has been previously reported in literature in only one diagnosed case [5]. To the best of our knowledge, the case reported here is the first presentation of incidental aortic aneurysm detected with Tc-99m MAG3 which started from the ascending aorta and extended to the iliac bifurcation. The CT angiography findings (aortic aneurysm and mural thrombus) disclosed the renal scintigraphic features of suspected $A A$ and decreased cortical 


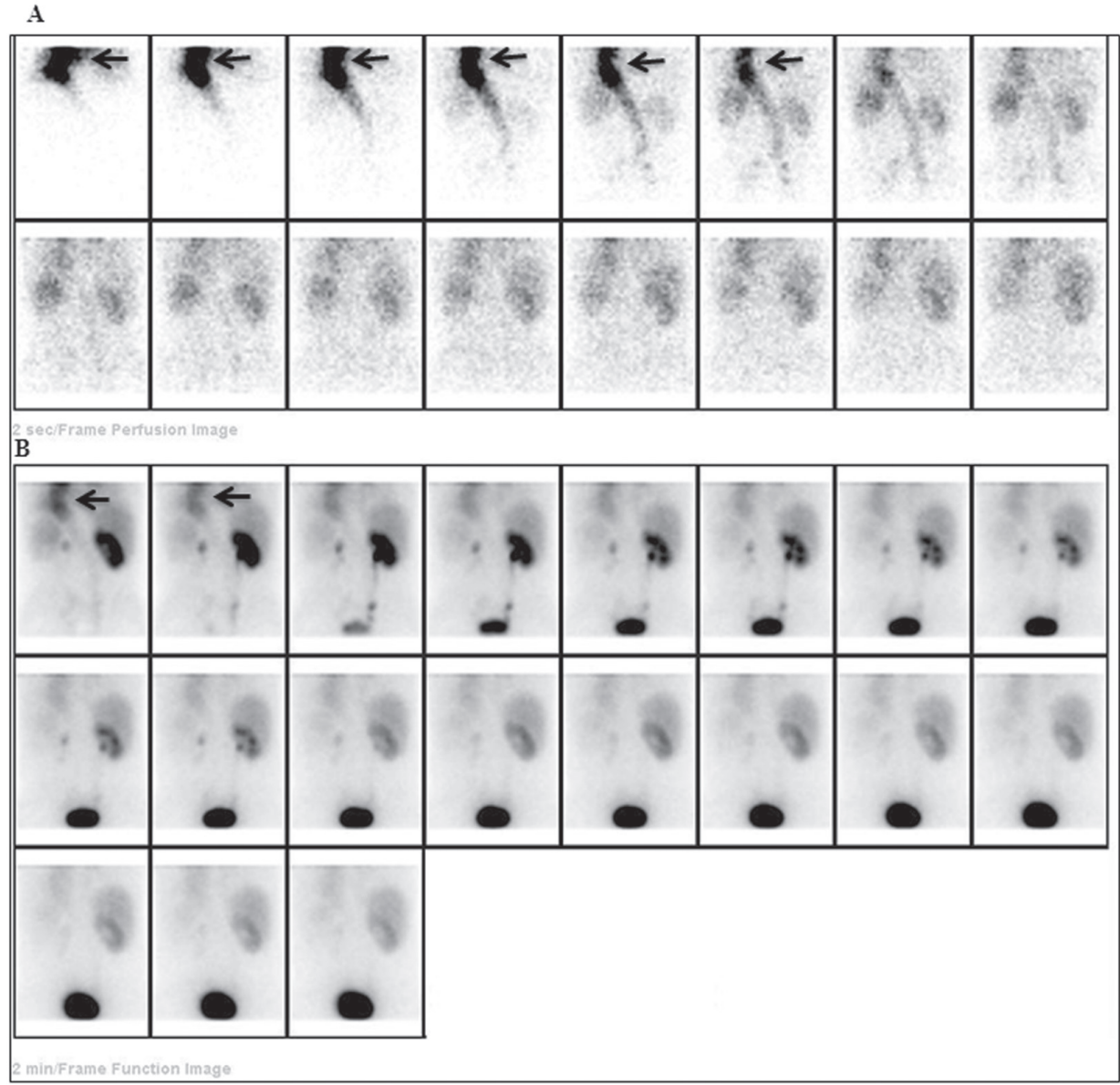

Figure 1.

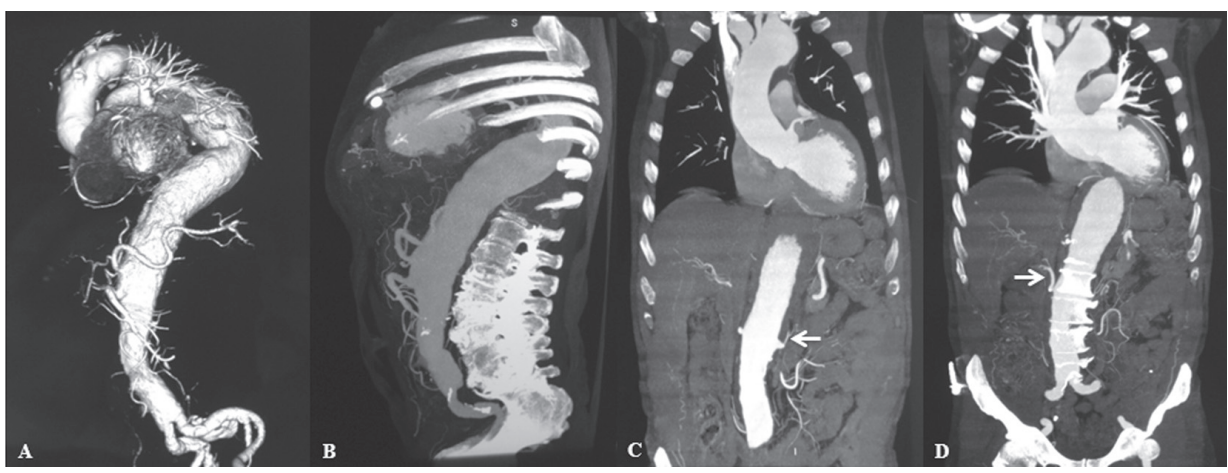

Figure 2.

radiotracer uptake, function and excretion of the left kidney. In the case presented here, the incidental detection of AA with Tc-99m MAG3 renal scintigraphy points at the importance of correlative imaging for the differential diagnosis of abnormal radioactivity accumulation in the region of vascular structures.

\section{Figure 4}

Chest X-Ray indicating aortic knob width and enlarged descending aorta (arrowheads).

\section{References}

1. Cornuz J, Sidoti Pinto C, Tevaearai H, Egger M. Risk factors for asymptomatic abdominal aortic aneurysm: systematic review and meta-analysis of population-based screening studies. Eur J Public Health 2004; 14: 343-349.

2. Kotze CW, Menezes LJ, Endozo R, Groves AM, Ell PJ, Yusuf SW. Increased metabolic activity in abdominal aortic aneurysm detected by $18 \mathrm{~F}$-fluorodeoxyglucose (18F-FDG) positron emission tomography/computed tomography (PET/CT). Eur J Vasc Endovasc Surg 2009; 38: 93-99.

3. Pande RL, Beckman JA. Abdominal aortic aneurysm: populations at risk and how to screen. J Vasc Interv Radiol 2008; 19: S2-S8. 


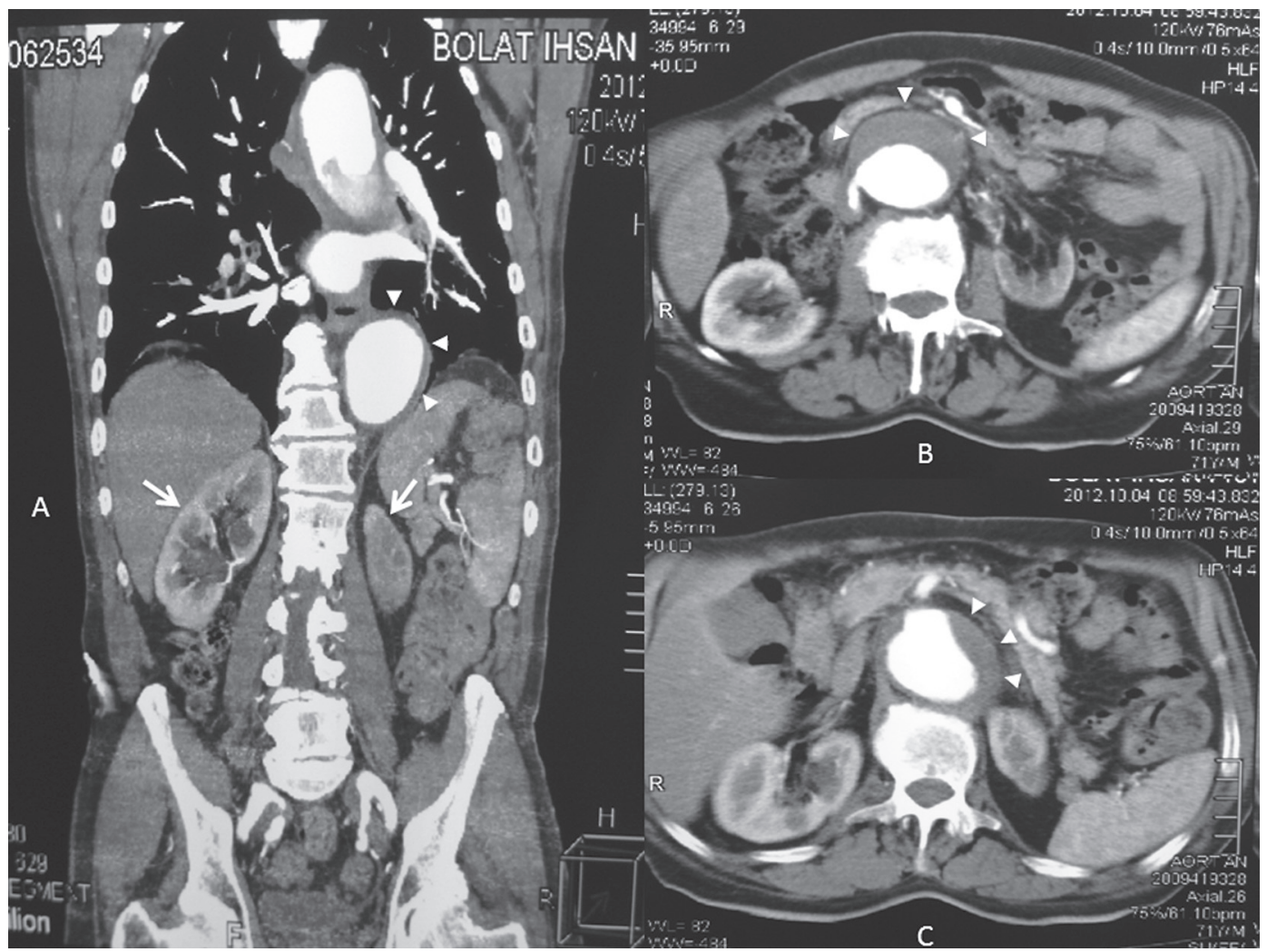

Figure 3.

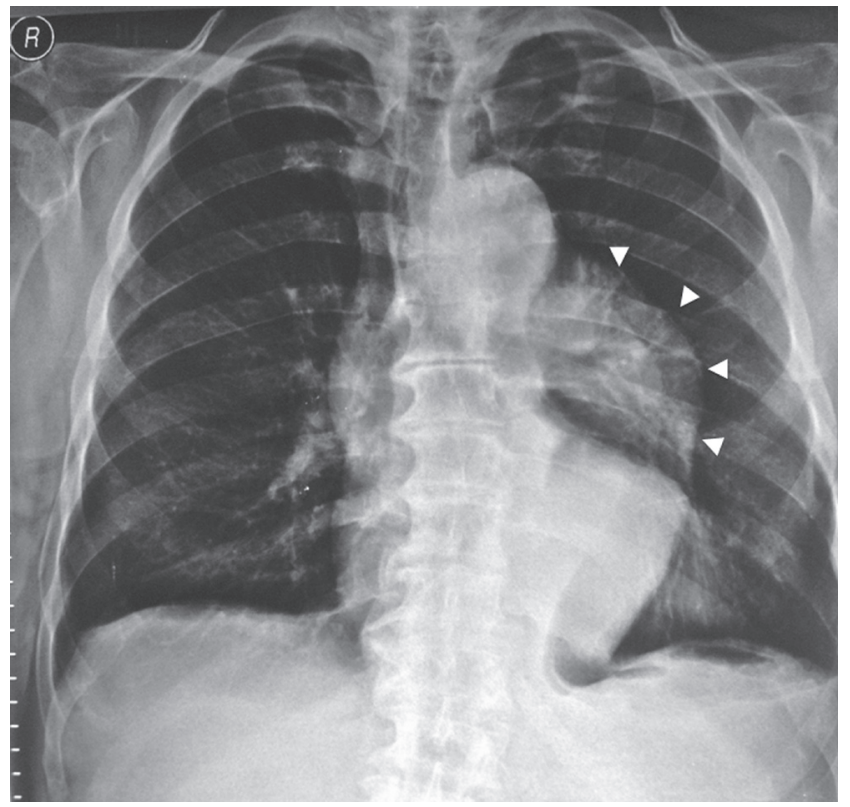

4. Prisant LM, Mondy JS 3rd. Abdominal aortic aneurysm. J Clin Hypertens (Greenwich) 2004; 6: 85-89.

5. Phisitkul S, Brian S, Rakvit A et al. Abdominal aortic aneurysm demonstrated on renal scintigraphy. Clin Nucl Med 2003; 28: 711-714.

6. Shih WJ, Pulmano C. Extrarenal abnormalities seen in 99mTc DTPA renal flow study. Semin Nucl Med 1989; 19: 69-71.

7. Raman V, Kapse N, Karugaba R et al. An unusual presentation of abdominal aortic aneurysm on static renal Tc-99m DMSA scintigraphy. Clin Nucl Med 2007; 32: 418-420.

8. Hidalgo Ramos FJ, Contreras Puertas P, Maza MuretFR, Portero De la Torre M, Del Real Nuñez R, Latre Romero JM. Descending thoracic and abdominal aortic aneurysm in perfusion ventilation scintigraphy. An incidental finding. Rev Esp Med Nucl 2010; 29: 271-272

9. Hsu CC, Huang YF, Chuang YW. Detection of an infected abdominal aortic aneurysm with three-phase bone scan and gallium-67 scan. Clin Nucl Med 2008; 33: 305-307.

Figure 4. 